\title{
Histopathological Differentiation Employing Endomyo- cardial Biopsy in the Clinical Assessment of Primary Myocardial Disease
}

\author{
Morie Sekiguchi, M.D. and Souji Konno, M.D.
}

\section{Summary}

By utilizing endomyocardial biopsy, the clinical diagnosis and classification of primary myocardial disease is possible. This procedure will immediately eliminate the possibility of such secondary myocardial diseases as sarcoidosis, amyloidosis, glycogen storage disease and myocarditis.

Histopathologic differentiation of primary myocardial disease was investigated by analyzing the pathologic and diagnostic significances of endocardial and myocardial lesions at probable sites of pathology of 126 autopsied or biopsied cases of different diseases and in numerous biopsy specimens from 173 cases of myocardial disease. At varying intervals following biopsy, 9 cases were autopsied. Biopsy and autopsy findings correlated well.

The following histopathological findings were noteworthy.

1. Endocardial thickening: This is a characteristic finding in endocardial fibroelastosis. Other endomyocardial discases can be diagnosed when various causal genetic factors are excluded.

2. Myocardial hypertrophy: Size of muscle fibers, fragmentation of myofibrils, vacuolization, pyknosis and pleomorphism of nuclei and derangement of muscle bundles should be noted.

Interstitial fibrosis accompanies the advanced cases.

3. Myocardial degeneration or fibrosis: Vacuolization, hydropic degeneration, swelling, pleomorphism, basophilic or mucoid degeneration and deposition of other abnormal substance are to be recorded. Artifacts should be disregarded.

When attempting to establish a histopathologic biopsy diagnosis, such factors as inflammatory, toxic, thrombogenic, anoxic, hemodynamic, mechanical and metabolic conditions should be excluded as far as possible.

It should be emphasized that an endomyocardial biopsy is one of the most important diagnostic means to determine the classification when combined with other diagnostic methods.

Finally, we must reaffirm that the negative biopsy report does not deny the presence of the disease.

\section{Additional Indexing Words :}

Idiopathic cardiomyopathy Idiopathic myocardial fibrosis Idiopathic hypertrophy of the heart Endocardial thickening Endocardial 
fibroelastosis Myocardial sarcoidosis Cardiac glycogenosis Myocarditis

DRIMARY myocardial disease is considered to represent a pathologic process primarily affecting the heart muscle. ${ }^{1)-4}$

This particular disease condition has been denoted as cardiomyopathy, ${ }^{5,6)}$ obscure cardiopathy, ${ }^{7}$ myocardosis, ${ }^{81}$ non-coronary cardiomyopathy, ${ }^{9}$ idiopathic hypertrophy of the heart, ${ }^{10}$ and idiopathic myocardial hypertrophy. ${ }^{11}$ Numerous reports have appeared in the literature to illustrate this condition. ${ }^{121-17)}$

Fowler ${ }^{1,2 y}$ limited the term to those conditions in the unknown idiopathic group and differentiated primary from secondary myocardial disease. Mattingly ${ }^{18), 19}$ preferred to include many known conditions affecting the myocardium such as amyloidosis, hemochromatosis, glycogen storage disease, and sarcoidosis.

We consider that the term primary myocardial disease refers to those disorders of diverse and obscure etiology primarily involving the myocardium.

When making the diagnosis of primary myocardial disease, it is essential to understand the concepts of the disease, to be aware of those conditions within its scope and rule out other cardiac diseases. Since the application of our endomyocardial biopsy technique, ${ }^{20)-22)}$ we have secured numerous biopsies to establish the diagnosis of obscure myocardial disease and through this method the clinical diagnosis and classification of primary myocardial disease was possible. ${ }^{23)}$ This procedure will immediately eliminate the possibility of such secondary myocardial disease as sarcoidosis, amyloidosis, glycogen storage disease, and myocarditis.

However, the biopsies carried out on the numerous cases of clinically diagnosed primary myocardial disease revealed various histopathological findings. Recently, owing to the more extensive use of endomyocardial biopsy for diagnosis of this disease condition, problems have arisen in making accurate histopathological interpretation. The authors admit that the diagnosis of primary myocardial disease cannot be made only by the biopsy findings, and have been perplexed in arriving at the diagnosis even by this method, for the histopathological findings are not considered specific for primary myocardial disease.

The present report is an attempt to differentiate such histopathological lesions by comparing the findings with various known heart diseases and other conditions affecting the myocardium. 


\section{Materials and Methods}

As have been reported, ${ }^{20)-22)}$ the common sites of the biopsy are the apex or outflow tract of the right ventricle, the lateral anterior or internal dorsal aspect of the septum of the right atrium, and the apex of the left ventricle. At first, from these sites, normal or abnormal histopathological specimens were investigated in normal hearts or in hearts where disease conditions with or without cardiac involvement were present and from various age groups. Then, an analysis on the pathogenesis of endocardial and myocardial lesions was performed in 126 autopsied or biopsied cases. Thereafter, a survey was completed on biopsy specimens from 173 cases of myocardial disease.

The specimens were fixed in 10\% formalin or buffered neutral formalin (Lillie) routinely, and when necessary, in absolute alcohol. The sections were prepared in the usual manner and stained with hematoxylin-eosin, Masson's trichrome or Mallory's stain, Weigert van Gieson's stain for elastica and collagen, and phosphotungstic acid hematoxylin. PAS, colloidal iron, alcian blue, toluidin blue metachromasia, and oil red $\mathrm{O}$ stain were also applied whenever it was needed.

\section{Results}

By virtue of the endomyocardial biopsy, we could differentiate such secondary myocardial diseases as myocarditis, myocardial sarcoidosis or giant cell myocarditis (Fig. la) and glycogen storage disease (Pompe's disease, Fig. lb). Most of the cases of clinically diagnosed primary myocardial disease however, revealed non-specific endo- or myocardial changes. Therefore, the authors classified the lesions into three groups according to their histopathological patterns.

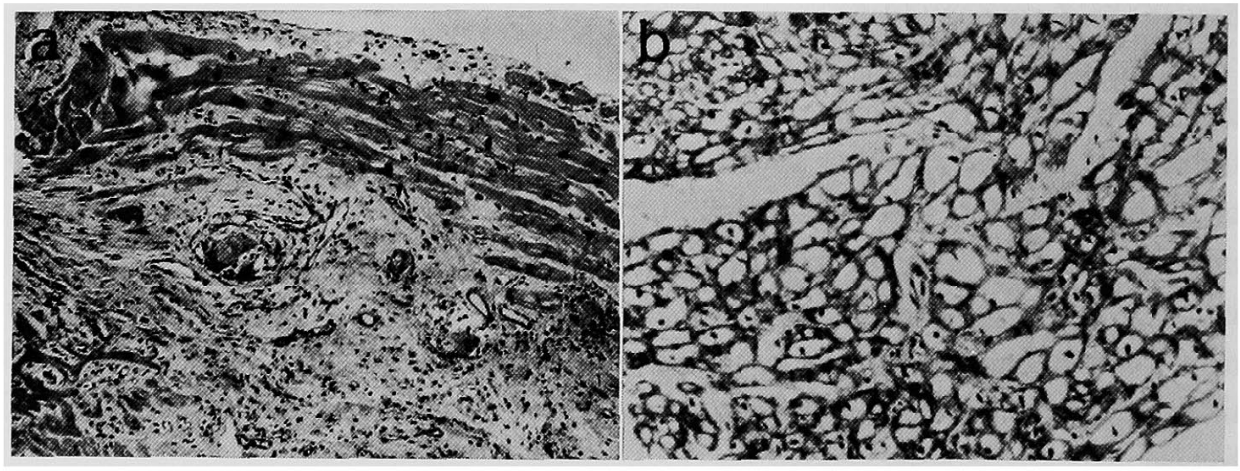

Fig. 1. a) Myocardial sarcoidosis. In the fibrotic myocardium, infiltration of lymphocytes, epithelioid cells, and giant cells containing asteroid bodies are observed. Biopsy from the right ventricle of a 38-year-old female (Hematoxylin-eosin stain).

b) Cardiac glycogenosis (Pompe's disease). Large vacuoles showing lace work structure. Biopsy from the left ventricle of a one-year-old male (Hematoxylin-eosin stain). 
(1) Endocardial thickening

Initially, physiologic endocardial thickening should be disregarded. According to our investigation, more than $20 \mu$. of right atrium and $10 \mu$. of either right or left ventricle in adult hearts are considered abnormal but the sites where the biopsies are performed must be taken into consideration. Nagayo, ${ }^{24)}$ MacMillan and Lev, ${ }^{25)}$ and Okada' ${ }^{26)}$ reports were referred for the recognition of pathological endocardial thickening.

Endocardial fibroelastosis of infancy: Five cases were diagnosed as primary infantile endocardial fibroelastosis. ${ }^{27)-29)}$ All cases had a clear cut distinction between the thickened lamellar endocardium and underlying myocardium (Fig. 2a). They were rather easily differentiated from other groups.

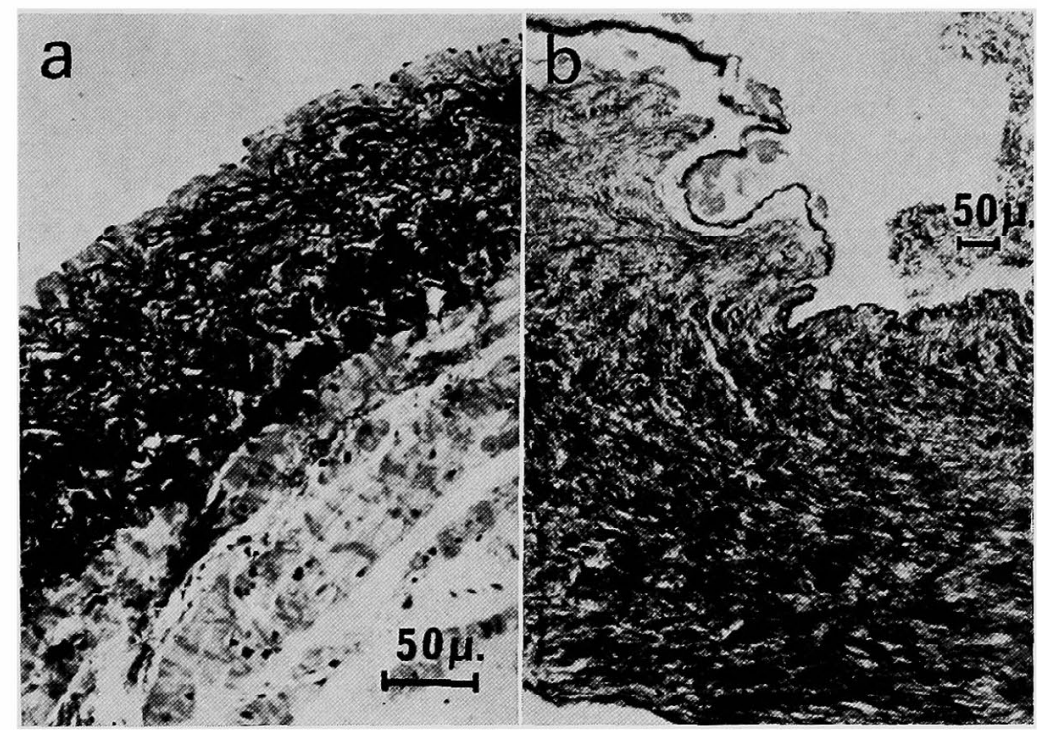

Fig. 2. a) Primary infantile endocardial fibroelastosis. There is a sharp distinction between the thickened lamellar endocardium and the underlying myocardium. Biopsy from the left ventricle of a 4-year-old female (Weigert-van Gieson's stain).

b) Endocardial fibroelastosis in the adult. Biopsy from the left ventricle of a 14-year-old female (Weigert-van Gieson's stain).

Endomyocardial fibrosis: The so-called endomyocardial fibrosis includes various conditions such as Davies' disease, ${ }^{30 /-34)}$ diffuse endomyocardial sclerosis (Lynch and Watt $\left.{ }^{351}\right)$, endocarditis parietalis fibroplastica (Löffler ${ }^{36)}$ ), and cardiovascular collagenosis with parietal endocardial collagenosis (Becker $\left.{ }^{37}\right)$. One of the authors (S.K.) performed the biopsy in 2 cases of Davies' disease in Uganda in 1964, but we have not encountered these other rare conditions. We have had numerous cases of indistinct endomyocardial fibrosis which can 
be classified under non-specific endomyocardial fibrosis. They were differentiated into the 5 types according to Okada's classification. ${ }^{26)}$ There was structureless fibrosis (10 instances, Fig. 3a), fibroelastosis (10, Fig. 2b), thickening of subendothelial layer (15), thickening of all of the 5 layers (15, Fig. 3b) and thickening of subendocardial layer (30, Fig. 3c). Ten cases were considered to have mural thrombosis. Most of the cases were accompanied by degenerative or fibrotic lesions of the subendocardial myocardium (Fig. 3).

Control studies from autopsies revealed various kinds of endocardial

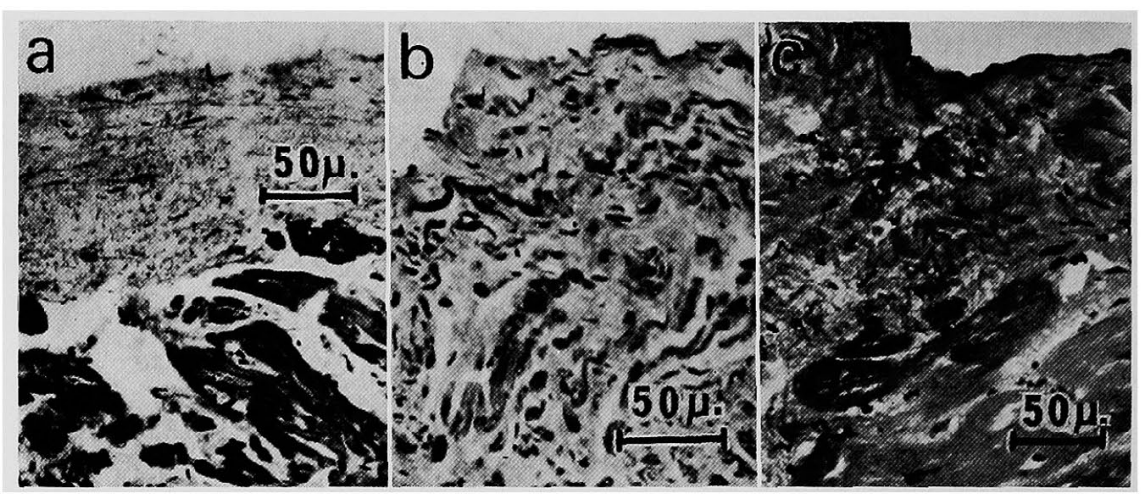

Fig. 3. Endocardial thickening in primary myocardial disease.

a) Structureless fibrosis. Biopsy of the right atrium in a case of a 22year-old male (Hematoxylin-eosin stain).

b) Thickening of the 5 layers. Biopsy of the right ventricle in a 34year-old male (Hematoxylin-eosin stain).

c) Subendocardial fibrosis. Biopsy of the left ventricle in a 32-year-old male (Hematoxylin-eosin stain).

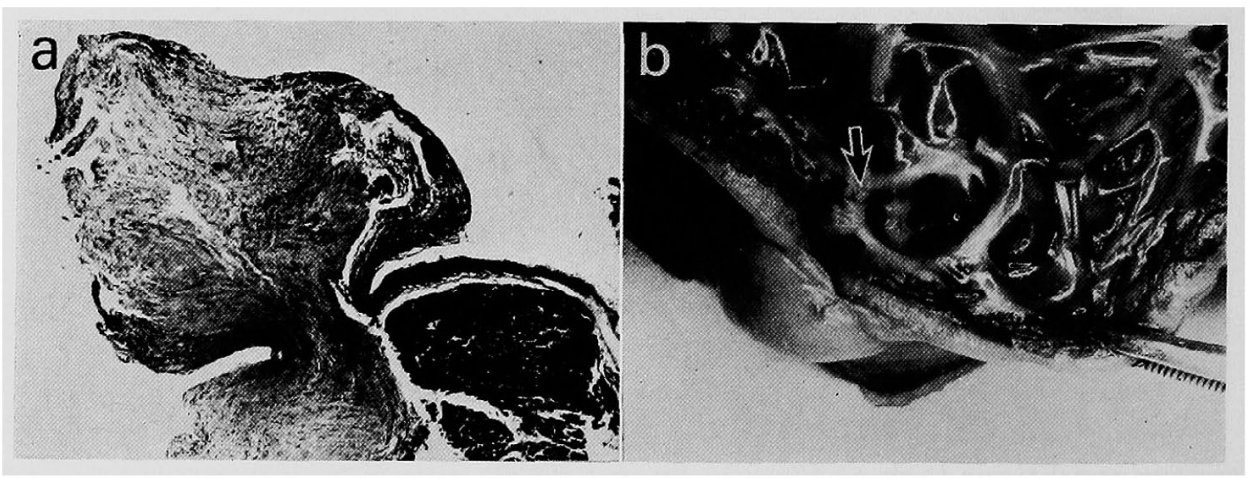

Fig. 4. Case 4 in Table I.

a) Biopsy from the apex of the right ventricle showing endocardial thickening. Since the other specimen did not reveal abnormal thickening, it was considered localized (Hematoxylin-eosin stain).

b) A patch of endocardial fibrosis which might be present at the time of biopsy that was confirmed 5 weeks later at autopsy. The arrow points to the area of previous biopsy. 


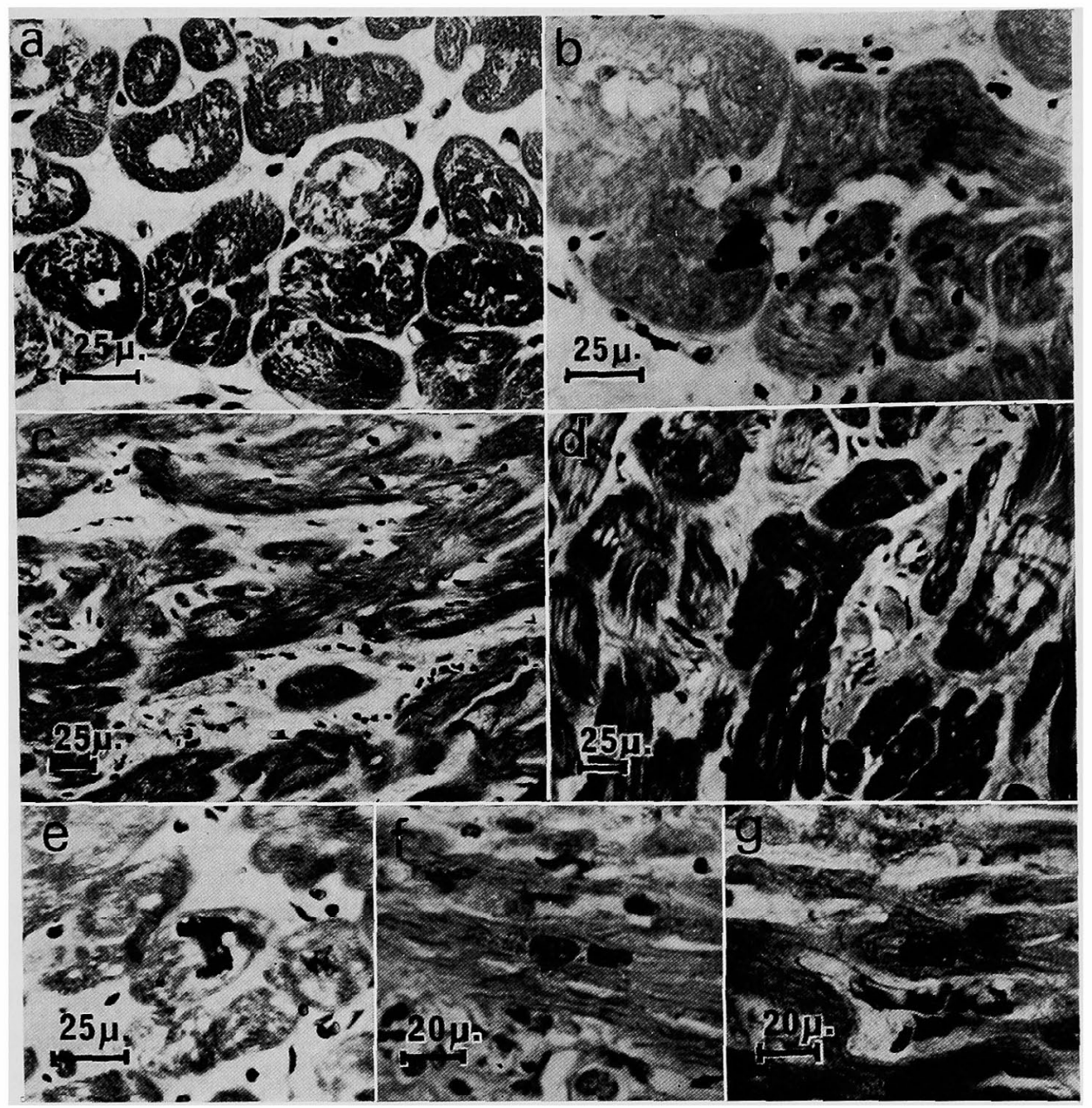

Fig. 5. Myocardial hypertrophy in primary myocardial disease.

a) Note fragmentation or looseness of myofibrils and vacuolization. Biopsy from the right ventricle in a 16-year-old male (Hematoxylin-eosin stain).

b) Swelling, vacuolization, and pyknosis of nuclei are observed. Biopsy from the right ventricle in a 19-year-old male (Hematoxylin-eosin stain).

c) Derangement of muscle bundles, and interstitial fibrosis associated with proliferation of fibroblasts are noted in a more advanced case. Biopsy from the right ventricle in a 19-year-old female (Hematoxylin-eosin stain).

d) Note the interstitial fibrosis. Biopsy from the left ventricle in a 33 year-old male (Hematoxylin-eosin stain).

e) Horseshoe shaped nucleus. Biopsy of the right ventricle in a 16 year-old male. (Hematoxylin-eosin stain).

f) Double nuclei in juxtaposition at their long axes. Biopsy from the left ventricle in a case of 25-year-old male (Masson's trichrome stain).

g) Double nuclei in juxtaposition at their short axes (Same case as Fig. 5f). 
thickening of a rather apparent causal-genetic relationship as described by Okada. ${ }^{26)}$ They were due to thrombogenic, hemodynamic, inflammatory, and metabolic factors.

In our biopsy series, one case revealed localized endocardial thickening in which one of the 2 specimens from the right ventricle revealed marked endocardial thickening, while the other did not exhibit abnormal thickening. This case was proven to be localized endocardial thickening in an autopsy performed 5 weeks later (Fig. 4).

(2) Hypertrophy of the myocardium

When evaluating the presence of myocardial hypertrophy, it is essential to measure the breadth of myocardial cells. ${ }^{381-41)}$ According to our study, over $15 \mu$. is considered hypertrophic. Histopathologically, the hypertrophied heart muscle cells revealed an increase in breadth, fragmentation or looseness of myofibrils, vacuolization, and pleomorphism of nuclei such as swelling, pyknosis, variety in size, deformity in dumbbell or cudgel shape or various other abnormalities. Double nuclei were quite frequently observed and they would be contiguous either at their long or short axes (Fig. 5).

In 30 out of 60 cases of hypertrophy, there was no apparent fibrosis, however, the remainder of the cases revealed varying degrees of fibrosis. In advanced cases, derangement of muscle bundles was observed (Fig. 5c, 5d).

(3) Myocardial degeneration and fibrosis

Contractile change of the myocardial cells was frequently observed (Fig. 6a). Sometimes this was confused with a degenerative change such as hydropic or hyaline degeneration. Nevertheless, various degenerative changes were also observed. These amounted to swelling or disappearance of myofibrils, vacuolar degeneration, hydropic degeneration, acidophilic degeneration, deposition of abnormal substance as basophilic or mucoid degeneration and or homogenous substance. Nuclei also revealed pyknosis, swelling, and pleomorphism in size and shape (Fig. 6).

Severe hydropic degeneration was seen in a case of a 6 -months-old boy who displayed some clinical evidence of suspective myocarditis. Glycogen was not demonstrated in this case (Fig. 6d). Rather advanced vacuolar degeneration was also observed in 2 cases. One was a case of 7-year-old girl who was proved to have endo-myocarditis through endomyocardial biopsy 2 months prior (Case 2 in Table I, Fig. 7b).

The other was that of a 24-year-old male who gave clinical evidence of suspective viral myocarditis. A case of a 30-year-old house wife, diagnosed as postpartum cardiomyopathy ${ }^{42)-44)}$ revealed accumulation of homogenous or granular substance in the myocardial cells. The substance had diffuse stainability or granular appearance and was mainly located in widened sarcoplasmic 
spaces. This substance was identified electronmicroscopically as fine, filamentous structure varying from $50-75 \AA$ in diameter. By histochemical survey, it was considered as an accumulation of abnormal glycoprotein (Fig. 6e). Basophilic or mucoid degeneration was also observed in the same specimen and also in 2 other cases. All of the 3 cases revealed evidence of marked cardiomegaly and congestive heart failure.

In the control studies, the biopsy in one case of iron deficiency anemia with a hemoglobin of $5.2 \mathrm{Gm} . / 100 \mathrm{ml}$, revealed vacuolization of myocardial cells (Fig. 6b), and was negative for fat stain. The above described degenerative changes, except for abnormal homogenous substance, were seen in various conditions of the hearts in the control group.

Interstitial edema was another change frequently obscrved, however, according to our dog experiment, it was considered as artifactual to some extent. Twenty cases were considered to be pathognomonic. Ten of the 20 cases were associated with proliferation of mononuclear cells including small round cells or fibroblasts. Fibrosis consisting of collagenous fibers was associated with the above described various degenerative changes of the myocardial cells. The fibrosis in the early stages consisted of fine collagenous fibers with some proliferation of fibroblasts, and then developed into advanced fibrosis even replacing most of the space to make island like myocardial cells (Fig. 6f, 6g).

Fig. 6. Myocardial degeneration and fibrosis.

a) Note a contractile change of myocardial cells. Biopsy of the right ventricle in a 47-year-old male (Mallory's stain).

b) Vacuolar degeneration in a case of iron deficiency anemia. Biopsy from the right ventricle in a 23-year-old female (Masson's trichrome stain).

c) Swelling of myocardial cells consisting of vacuolization and pleomorphism of nuclei is observed. Biopsy from the right ventricle in a 18-yearold female (Hematoxylin-eosin stain).

d) Hydropic degeneration in a case of suspected myocarditis. Biopsy from the left ventricle in a case of 6-months-old male (Hematoxylin-eosin stain).

e) Deposition of basophilic substance (B), and homogenous or granular substance (P) are observed in widened sarcoplasmic spaces. Biopsy from thr right ventricle in a 30 -year-old female (Hematoxylin-eosin stain).

f) Myocardial degeneration with accompanying fibrosis. Biopsy of the right ventricle in a 18-year-old female (Hematoxylin-eosin stain).

g) Advanced myocardial fibrosis replacing most of the space with island like myocardial cells. Biopsy from the right ventricle in a case of 5-ycarold male (Masson's trichrome stain).

h) Interstitial edema associated with proliferation of a few mononuclear cells is noteworthy. Hydropic degeneration of myocardial cells is also seen. This case (Case 2 in Table I) was proven to have endo-myocarditis 2 months prior. Biopsy from the right atrium (Hematoxylin-eosin stain). 
It is noteworthy that the 3 cases which revealed endocardial or myocardial fibrosis gave a past history of diphtheria without concomitant evidence of myocarditis at the time of the infection.

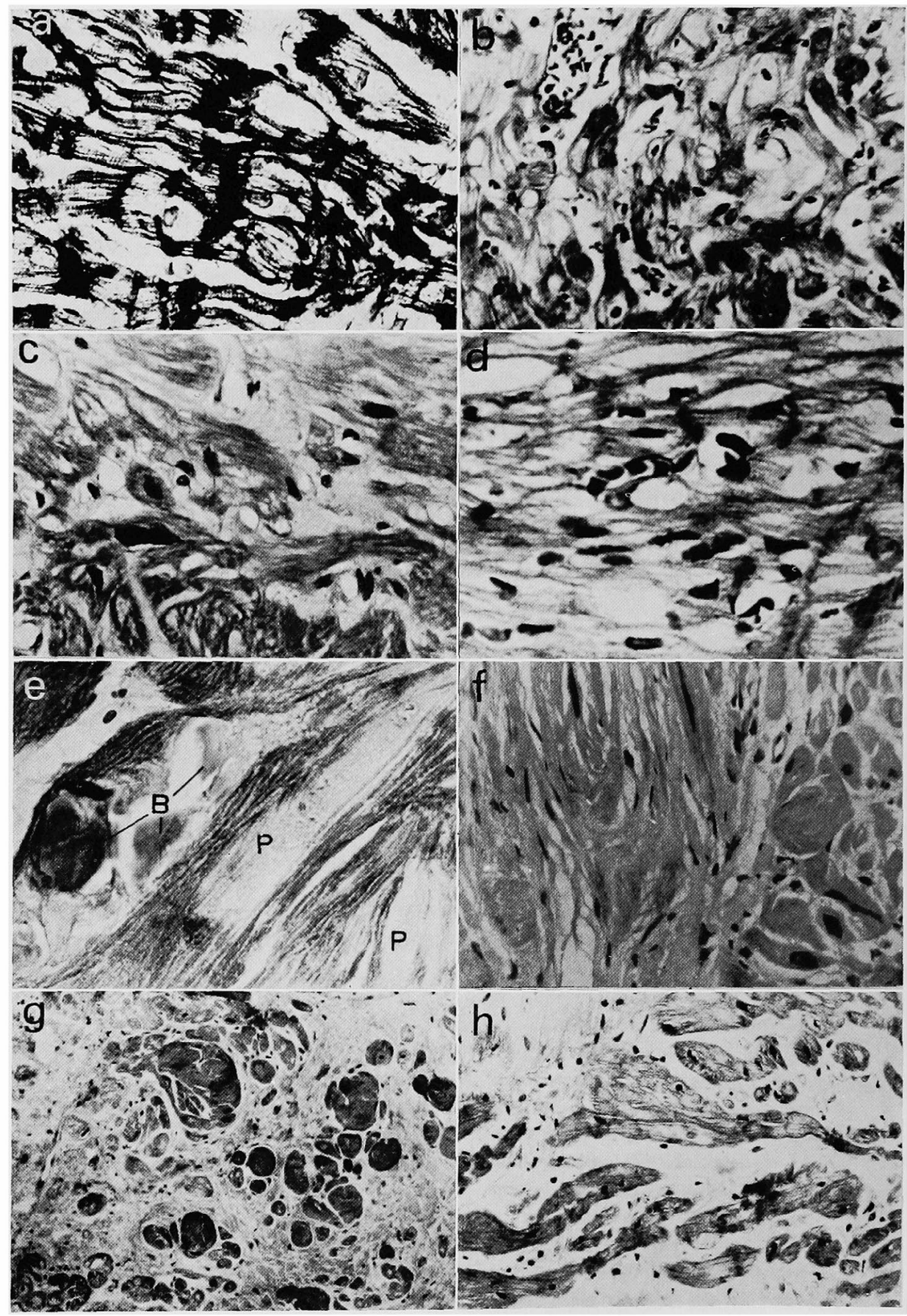


Biopsy and Autopsy:

At varying intervals following the biopsy, 9 cases were autopsied.

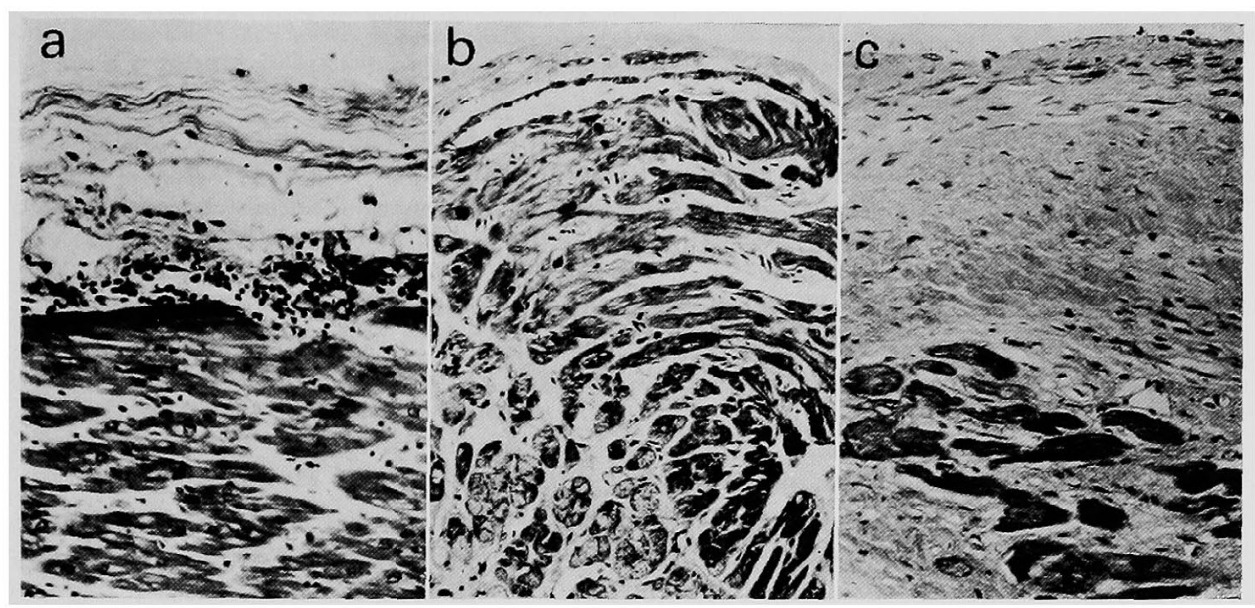

Fig. 7. Case 2 in Table I.

a) First biopsy from the right ventricle shows a proliferation of small round cells in the endocardial, subendocardial and adjacent myocardial spaces (Hematoxylin-eosin stain).

b) Second biopsy from the right ventricle. There is no active inflammatory change. Instead, slight endocardial thickening, interstitial edema, and vacuolar degeneration are observed (Hematoxylin-eosin stain).

c) Autopsy reveals marked endocardial thickening and interstitial fibrosis of the myocardium (Masson's trichrome stain).

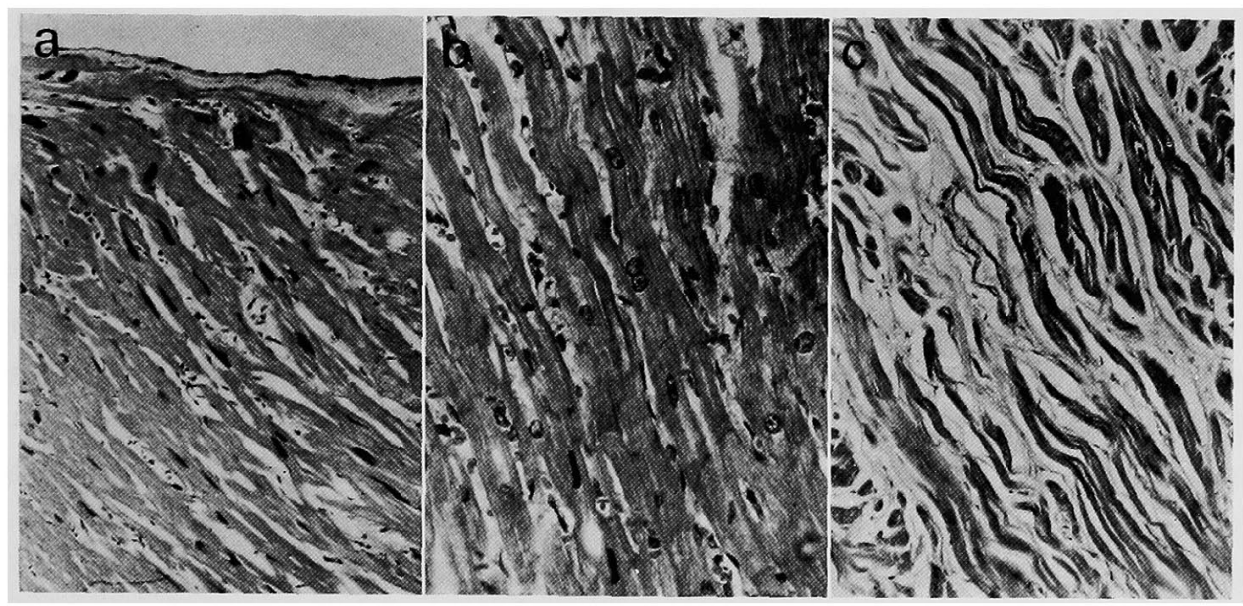

Fig. 8. Case 5 in Table I.

a) First biopsy from the right ventricle reveals myocardial hypertrophy and degeneration with pyknotic nuclei (Hematoxylin-eosin stain).

b) Second biopsy from the left ventricle. Myocardial hypertrophy is observed (Hematoxylin-eosin stain).

c) Autopsy performed 3 years later disclosed advancement of interstitial fibrosis and attenuated myocardial cells (Hematoxylin-eosin stain). 
Table I. Endomyocardial

\begin{tabular}{|c|c|c|c|c|}
\hline $\begin{array}{l}\text { Case } \\
\text { No. }\end{array}$ & Age & Sex & Clinical Diagnosis & First Biopsy Findings \\
\hline 1 & $30 \mathrm{yr}$. & $\mathbf{M}$ & Primary myocardial disease & Endo-myocardial fibrosis \\
\hline 2 & $7 \mathrm{yr}$. & $\mathrm{F}$ & Myocarditis & Endo-myocarditis \\
\hline 3 & $19 \mathrm{yr}$. & $\mathrm{F}$ & Familial cardiomyopathy & $\begin{array}{l}\text { Myocardial fibrosis and endocardial } \\
\text { thickening }\end{array}$ \\
\hline 4 & $45 \mathrm{yr}$. & $\mathrm{F}$ & $\begin{array}{l}\text { Primary myocardial disease } \\
\text { (Postpartal heart failure) }\end{array}$ & $\begin{array}{l}\text { Localized endocardial thickening } \\
\text { and myocardial fibrosis }\end{array}$ \\
\hline 5 & $22 \mathrm{yr}$. & $\mathbf{M}$ & Primary myocardial disease & $\begin{array}{l}\text { Myocardial hypertrophy, degenera- } \\
\text { tion and endocardial thickening }\end{array}$ \\
\hline 6 & 38 yr. & F & Myocardial sarcoidosis & Myocardial sarcoidosis \\
\hline 7 & $4 \mathrm{mo.}$ & $\mathbf{M}$ & $\begin{array}{l}\text { Bland, White and Garland } \\
\text { syndrome }\end{array}$ & $\begin{array}{l}\text { Endocardial fibroelastosis and myo- } \\
\text { cardial degeneration }\end{array}$ \\
\hline 8 & $4 \mathrm{mo}$. & $\mathbf{M}$ & Endocardial fibroelastosis & Endocardial fibroelastosis \\
\hline 9 & $\begin{array}{l}1 \mathrm{yr} . \\
9 \mathrm{mo} .\end{array}$ & $\mathbf{M}$ & $\begin{array}{l}\text { Glycogen storage disease } \\
\text { (Pompe's disease) }\end{array}$ & $\begin{array}{l}\text { Vacuolar degeneration } \\
\text { (Lace work structure) }\end{array}$ \\
\hline
\end{tabular}

They are listed in Table I. Four of these had been biopsied on 2 occasions. In case 2 , the first biopsy revealed marked cellular infiltration in the endocardial and subendocardial space and was considered to be endomyocarditis. Two months later, a biopsy from the same area showed vacuolar degeneration, interstitial edema and proliferation of a few mononuclear cells. Autopsy performed 4 months after the first biopsy revealed marked endocardial thickening and advanced myocardial fibrosis showing what one might call idiopathic myocardial fibrosis (Fig. 7). In case 4, myocardial hypertrophy and degeneration with pyknosis of nuclei were observed in the first biopsy, with the second biopsy displaying endocardial thickening and myocardial hypertrophy. This patient died suddenly on the street 3 years and 10 months after the first biopsy, and the autopsy disclosed advanced interstitial fibrosis and attenuated myocardial fibers suggesting that there was advancement of the fibrosis during that period (Fig. 8). Biopsy and autopsy findings also correlated well in other cases.

\section{Discussion}

The clinical diagnosis of primary myocardial disease can reasonably be made by means of careful history taking, physical examination, chest roentgenogram, electrocardiogram, vectorcardiogram, phonocardiogram, cardiac catheterization, and angiocardiography, although the signs vary widely. It 
Biopsy and Autopsy

\begin{tabular}{|c|c|c|}
\hline $\begin{array}{l}\text { Second Biopsy Findings } \\
\text { (Interval after the first biopsy) }\end{array}$ & $\begin{array}{l}\text { Interval after the First } \\
\text { Biospy at Autopsy }\end{array}$ & Autopsy Findings \\
\hline & 8 days & $\begin{array}{l}\text { Myocardial fibrosis and endo- } \\
\text { cardial fibrosis }\end{array}$ \\
\hline $\begin{array}{l}\text { (2 months) } \\
\text { Myocardial degeneration }\end{array}$ & 4 months & $\begin{array}{l}\text { Myocardial fibrosis and endo- } \\
\text { cardial fibrosis }\end{array}$ \\
\hline (1 month) & 27 days & Endomyocardial fibrosis \\
\hline & 5 weeks & $\begin{array}{l}\text { Localized endocardial thicken- } \\
\text { ing and myocardial fibrosis }\end{array}$ \\
\hline $\begin{array}{l}\text { (2 months) } \\
\text { Endocardial thickening and }\end{array}$ & 3 years and 10 months & $\begin{array}{l}\text { Myocardial fibrosis and endo- } \\
\text { cardial fibrosis }\end{array}$ \\
\hline & 1 week & Myocardial sarcoidosis \\
\hline & 2 weeks & $\begin{array}{l}\text { Myocardial necrosis, fibrosis and } \\
\text { endocardial fibroelastosis }\end{array}$ \\
\hline & 3 days & Endocardial fibroelastosis \\
\hline $\begin{array}{l}(2 \text { weeks }) \\
\text { Lace work structure with } \\
\text { abundant glycogen }\end{array}$ & 3 months & $\begin{array}{l}\text { Glycogen storage disease } \\
\text { (Pompe's disease) }\end{array}$ \\
\hline
\end{tabular}

was concluded that the addition of endomyocardial biopsy would be of potential value in making a more detailed clinical diagnosis. So, the authors performed biopsies on 173 cases of suspected myocardial disease. Of these, 3 cases were considered as giant cell myocarditis or myocardial sarcoidosis, ${ }^{45-48)}$ one case as cardiac glycogenosis (Pompe's disease), ${ }^{571-601}$ and 5 cases as either endomyocarditis or suspective myocarditis. In these cases, the biopsies were of definite diagnostic usefulness, but since endomyocardial lesions in the idiopathic group are nonspecific, a precise diagnosis could not be made by biopsy alone.

When making the diagnosis of primary myocardial disease, the clinical course and all findings from other diagnostic methods in addition to endomyocardial biopsy should be included.

Histopathological classification was attempted from an analysis of the biopsy specimens of those diagnosed as primary myocardial disease.

(1) Endocardial thickening

The diagnosis of primary infantile endocardial fibroelastosis can be made rather easily when one is aware of the presence of associated cardiovascular lesions, since endocardial fibroelastosis is often associated with other cardiovascular anomalies, particularly those in which a mechanical factor such as increased flow or pressure is present. ${ }^{41-51)}$

Endocarditis parietalis fibroplastica (Löffler), ${ }^{36)}$ cardiovascular collagenosis with pariental endocardial thrombosis (Becker), ${ }^{37 /}$ endomyocardial fibrosis 
(Davies), ${ }^{301-35)}$ and diffuse endomyocardial sclerosis (Lynch and Watt) ${ }^{35)}$ can be diagnosed and differentiated histopathologically as Davies proposed. ${ }^{34}$ ) Konno performed biopsies in patients with endomyocardial fibrosis in Uganda in which a thickened endocardium was obtained. We have not had other specific endomyocardial diseases, as described above, in our biopsy series however. Endocardial thickening other than a specific form, nevertheless, was rather frequently observed. These manifested various histopathological patterns, such as, structureless fibrosis, fibroelastosis, thickening of subendothelial layer, thickening of all of the 5 layers, and thickening of the subendocardial layer. Pathogenesis of such lesions should be due to cardiac dilatation, mechanical (flow or pressure), metabolic, toxic, thrombogenic, and inflammatory agents, ${ }^{26)}$ whereas, in some instances causal genetic factors may be indicated by the biopsy findings.

When results were equivocal for a primary lesion, it would be listed as nonspecific endomyocardial fibrosis. However, some of these could be referred to as endocardial fibroelastosis of adolescents and adults. ${ }^{50)}$ As most of the cases were associated with myocardial degeneration or fibrosis, they may be considered to be secondary endocardial lesions. ${ }^{26,49)-51\}}$ It should be noted that some of the cases of this group revealed a restrictive type cardiomyopathy as described by Goodwin. ${ }^{6)}$

(2) Myocardial hypertrophy

Assessment of myocardial hypertrophy can be made primarily by measuring the breadth of each myocardial cell. There have been many reports to make quantitative estimation of myocardial hypertrophy. ${ }^{38-41)}$ Whether the specimen taken by our biotome would represent the true nature or not presents a new problem. Kawai and associates ${ }^{52), 53)}$ compared the breadth of the myocardial cells of endomyocardial biopsy and from myocardial biopsy taken at heart surgery from various heart diseases and reported that they corresponded fairly well. It should be noted then that the myocardial cells on the surface of the myocardial trabecle are more hypertrophic than those of the inner layer.

As for the qualitative analysis, swelling, fragmentation or looseness of myofibrils, vocuolization, pleomorphism of nuclei including double nuclei, and derangement of muscle bundles have been reported. Detailed morphological descriptions of hypertrophied muscle were made by Linzbach ${ }^{39}$ and Nieth. ${ }^{40)}$ They described an increase of sarcoplasm, irregularly shaped myocardial cells, coagulated myofibrils, vacuolar degeneration, basophilic degeneration, fatty degeneration, and pigmentation. Nuclei were recorded as having swelling, change of chromatin, dumbbell, cudgel or horseshoe-shape deformities, fragmentation, or arranged in juxtaposition. Whether these 
changes would designate amitotic cell division ${ }^{54), 55)}$ or not will wait further confirmation. Multiplication of nuclei has also been reported in atrophic hearts. $^{38)}$ In our study, in cases of advanced myocardial hypertrophy, various degrees of myocardial degeneration and interstitial fibrosis were found.

(3) Myocardial degeneration

Hydropic or vacuolar degeneration was frequently observed. At first, it was thought that these were the result of circulatory disturbances or anoxia, for the lesion was seen in cases of congestive heart failure, surrounding area of myocardial necrosis following infarction, and various other conditions causing myocardial damage. ${ }^{56}$ In addition, we were able to confirm by serial biopsy that this degeneration was a histopathological manifestation of myocarditis. This finding which was seen in a case of cardiac glycogenosis (Pompe's disease $)^{57-60)}$ as a lace work structure (Fig. 1b), histochemically disclosed the presence of increased glycogen. In addition, swelling or fragmentation of myofibrils, and acidophilic degeneration were commonly observed. Pyknosis, swelling, and pleomorphism of nuclei were the same as those described in hypertrophied muscle. Deposition of basophilic substance was uncovered in various conditions of the heart such as hypertrophy, myocardosis, and hypothyroidism. ${ }^{1,611-63)}$ Deposition of homogenous substance was rarely found. In one of our cases, histochemical and electronmicroscopic study revealed a peculiar fibrous structure with a rather increased amount of glycogen, which was considered as glycoprotein. ${ }^{44), 64)}$ A similar peculiar fibrous structure was found electronmicroscopically in Ferrans, ${ }^{65)}$ Takatsu ${ }^{66)}$ and their associates.

Interstitial edema was observed frequently, however, its pathogenesis was not verified in every case. In some cases it could be considered as evidence of myocarditis, congestive heart failure, or metabolic disturbance. It was often accompanied with fine collagenous fibers. Proliferation of fibroblasts was often noted, and this was believed due to some reparative process for the degenerated myocardial cells. Focal and advanced fibrosis consisting of thick collagenous fibers suggested preceding inflammation or chronic anoxia due to circulatory failure.

Endomyocardial Biopsy and Autopsy:

In the study of 9 cases, the findings obtained from the biopsies correlated well with those of autopsy (Table I). In case 2 and case 5 (Fig. 7, 8), the course of the disease process was confirmed. It must be emphasized that such information can only be obtained by the biopsy and the understanding of the pathogenesis of what we call primary myocardial disease.

Diagnostic problems of endomyocardial biopsy.

We wish to state that such disease as myocarditis, endocarditis, endecardial fibroelastosis, specific forms of endomyocardial disease, sarcoidosis, 
amyloidosis, and glycogen storage disease can be diagnosed by our biopsy method. On making the clinical diagnosis of primary myocardial disease, the biopsy gives us much additional information. Since the findings obtained from such specimens are almost exclusively non-specific, various other diagnostic methods should be employed to rule out other conditions for which various causal genetic factors as hemodynamic, ${ }^{26), 49), 511}$ anoxic, ${ }^{67)}$ inflammatory, ${ }^{68)-70)}$ nutritional, ${ }^{71)}$ metabolic, ${ }^{72), 73)}$ toxic, ${ }^{74)-78)}$ allergic, ${ }^{79}$ ) hereditary, ${ }^{13)}$ vascular, ${ }^{801,81)}$ and thrombogenic ${ }^{26)}$ agents may be implicated.

When the biopsy is attempted, the site of the biopsy is determined by the electrocardiographic pattern, which usually correlates well. Numerous and repeated biopsy specimens taken from various areas of the endocardium contribute more effectively to a correct diagnosis. Indeed, the serial biopsy becomes informative in establishing the diagnosis as well as anlyzing the pathogenesis of primary myocardial disease. It should also be emphasized that the negative biopsy record does not eliminate the presence of the disease.

Our biopsy method is becoming widely used irrespective of the diagnosis of primary myocardial disease, in the evaluation of indication of cardiovascular surgery, and in the pathophysiological analysis of congestive heart failure, thyroid disease and so on. Various methods for evaluation, such as histochemical, ${ }^{81-83)}$ electronmicroscopical, ${ }^{64)}$ and immunological ${ }^{84), 85)}$ survey can be applied to the biopsy specimen.

Eventually, the authors feel that the term "primary" myocardial disease will become obsolete owing to the progress of research in this particular disease condition.

\section{ACKNOWLEDGEMENT}

The authors express their gratitude to the members of the Department of Pathology in contributing to this investigation, and to Prof. K. Hirosawa for his interest and counsel.

\section{REFERENCES}

1. Fowler, N. O., Gueron, M., and Rowlands, D. T.: Girculation 23: 498, 1961.

2. Fowler, N. O.: Prog. Cardiovasc. Dis. 7: 1, 1964.

3. Massumi, R. A., Rios, J. C., Gooch, A. S., Nutter, D., De Vita, V. T., and Datlow, D. W.: Girculation 31: 19, 1965.

4. Friedberg, C. K.: Diseases of the Heart (3rd ed.), W. B. Saunders Co., Philadelphia and London, p. 992, 1966.

5. Hickie, J. B. and Hall, G. V.: Australian Ann. Med. 9: 2508, 1960.

6. Goodwin, J. F., Gordon, H., Hollman, A., and Bishop, M. B.: Brit. Med. J. 1: 69, 1961.

7. Evans, W.: Brit. Heart J. 19: 164, 1957.

8. Blankenhorn, M. A. and Gall, E. A.: Circulation 13: 217, 1956. 
9. Brigden, W.: Lancet 273: 1179 and 1243, 1957.

10. Levy, R. L. and Von Glahn, W. C.: Am. Heart J. 28: 714, 1944.

11. Spodick, D. H. and Littmann, D.: Am. J. Cardiol. 1: 610, 1958.

12. Mattingly, T. W.: J. A. M. A. 191: 127, 1965.

13. Evans, W.: Brit. Heart J. 11: 68, 1949.

14. Haupt, E. J. und Schmidt, J.: Arch. Kreislaufforsch. 55: 4, 1968.

15. Wolstenholme, G. E. W. and O'Conner, M.: Cardiomyopathies, J \& A Churchill Ltd., London, 1964.

16. Burch, G. E., Carlson, F. D., Davies, J. N. P., DePasquale, N., Ferrans, V., Fowler, N. O., Hibbs, R., Mattingly, T. W., Mogabgab, W., Sjoerdsma, A., and Walsh, J.: The Heart and Circulation. Second National Conference on Cardiovascular Diseases. Vol. 1/Research ed. by E. C. Andrus, Washington, D. C., p. 488, 1964.

17. Harvey, W. P, Segal, J. P., and Gurel, T.: Prog. Cardiovasc. Dis. 7: 17, 1964.

18. Mattingly, T. W.: Mod. Concepts Cardiovasc. Dis. 30:677 and 683, 1961.

19. Mattingly, T.W.: Circulation 32: 845, 1965.

20. Sakakibara, S. and Konno, S.: Jap. Heart J. 3: 537, 1962.

21. Konno, S. and Sakakibara, S.: Dis. Chest 44: 345, 1963.

22. Konno, S. and Sakakibara, S.: Bull. Heart Institute, Japan 1, 1966.

23. Hirosawa, K., Kondo, M., Shibuya, M., Takao, A., Konno, S., Sakamoto, A., Murasaki, F. Kusumoto, M., Saito, A., Sekiguchi, M., Shimoshige, Y., Kobayashi, S., Oota, R., Koono, S., Takahashi, S., and Misu, R.: Jap. Circulat. J. 31: 1945, 1967.

24. Nagayo, M.: Beitr. z. path. Anat. 45: 283, 1909.

25. McMillan, J. B. and Lev, M.: J. Gerontol. 14: 268, 1959.

26. Okada, R.: Jap. Heart J. 2: 220, 1961.

27. Anderson, D. H. and Kelly, J.: Pediatrics 18: 513, 1956.

28. Black-Schaeffer, B.: Arch. Path. 63: 281, 1957.

29. Moller, J. H., Lucas, R. V., Adams, P., Anderson, R. C., Jorgens, J., and Edwards, J. E.: Circulation 30: 759, 1964.

30. Connor, D. H., Somers, K., Maion, W. C., and D'Arbela, P. G.: Am. Heart J. 74: 687, 1967.

31. Connor, D. H. Somers, K., Maion, W. C., and D'Arbella, P. G.: Am. Heart J. 75: 107, 1968.

32. Davies, J. N. P.: East African M. J. 25: 10, 1948.

33. Davies, J. N. P. and Ball, J. D.: Brit. Heart J. 17: 337, 1955.

34. Davies, J. N. P.: Am. Heart J. 59: 600, 1960.

35. Lynch, J. B. and Watt, J.: Brit. Heart J. 19: 173, 1957.

36. Löffer, W.: Schweiz. Med. Wschr. 35: 817, 1936.

37. Becker, B. J. P., Chatgidakis, C. B., and Van Lingen, B.: Circulation 7: 345, 1953.

38. Karsner, H. T., Saphir, O., and Todd, T. W.: Am. J. Path. 1: 351, 1925.

39. Linzbach, A. J.: Virchows Arch. path. Anat. 314: 534, 1947.

40. Nieth, H.: Beitr. z. path. Anat. allg. Path. 110:618, 1949.

41. Henschel, E.: Virchows Arch. path. Anat. 321: 283, 1952.

42. Meadows, W. R.: Circulation 15: 903, 1957.

43. Walsh, J. J., Burch, G. E., Black, W. G., Ferrans, V. J., and Hibbs, R. G.: Circulation 32 : $19,1965$.

44. Hirosawa, K., Shibuya, M., Konno, S., Murasaki, F., Sekiguchi, M., and Kusumoto, M.: Jap. Circulat. J. 31: 835, 1967 (in Japanese).

45. Didion, H.: Virchows Arch. $310: 85,1943$.

46. Porter, G. H.: New Eng. J. Med. 263: 1350, 1960.

47. Ooneda, G., Mitomo, H., and Kanai, H.: Acta Path. Jap. 7: 591, 1957.

48. Sekiguchi, M., Konno, S., Kondo, M., and Hirosawa, K.: Jap. Circulat. J. 31: 987,1967 (in Japanese).

49. Okada, R., Glagov, S., and Lev, M.: Am. Heart J. 75: 474, 1968. 
50. Dyson, B. C. and Decker, J. P.: Arch. Path. 66: 190, 1958.

51. Fisher, E. R. and Davis, E. R.: Am. Heart J. 56: 553, 1958.

52. Kawai, C., Kunishige, K., Ochi, S., Inoue, K., Yamashita, K., Kurimoto, K., and Takatsu, T.: Jap. Circulat. J. 31 : 1946, 1967.

53. Takatsu, T. and Kawai, C.: Naika 21: 1061, 1968 (in Japanese).

54. Körner, F.: Zschr. Mikrosk. Anat. Forsch. 38: 441, 1935.

55. MacMahon, H. E.: Am. J. Path. 8: 845, 1937.

56. Gould, S. E.: Pathology of the heart (2nd ed.), Charles C. Thomas Pub., Springfield, Ill., p. $497,1960$.

57. di Sant' Agnese, P. A., Anderson, D. H., Mason, H. H., and Bauman, W. A.: Pediatrics 6: $402,1950$.

58. di Sant' Agnese, P. A.: Ann. New York Acad. Sc. 72: 439, 1959.

59. Van Creveld, S. and Huijing, F.: Am. J. Med. 38: 554, 1965.

60. Hug, G. and Schubert, W. K.: Arch. Path. 84: 141, 1967.

61. Doerr, W.: Zschr. Kreislaufforsch. 41: 42, 1952.

62. Scotti, T. M.: Am. J. Clin. Path. 25: 994, 1955.

63. Haust, M. D., Rowlands, D. T., Garancis, J. C., and Landing, B. H.: Am. J. Path. 40: 185, 1962.

64. Kawamura, K. and Hayashi, K.: Jap. Circulat. J. 30: 1575, 1966.

65. Ferrans, V. J., Hibbs, R. G., Walsh, J. J., and Burch, G. E.: Am. J. Cardiol. 17: 457, 1966.

66. Takatsu, T., Kawai, C., Tsutsumi, G., and Inoue, K.: Am. Heart J. 76: 93, 1968.

67. Johnson, F. R.: Arch. Path. 54: 237, 1952.

68. Saphior, O.: Arch. Path. 32: 1000, 1941.

69. Burch, G. E. and De Pasquale, N. P.: Cardiomyopathies, ed. by G. E. W. Wolstenholme and M. O'Connor, J \& A Churchill Ltd., London, p. 322, 1964.

70. Braimbridge, M. V., Darracott, S., Chayen, J., Bitensky, L., and Poulter, L. W.: Lancet i: $171,1967$.

71. Higginson, J., Gillanders, A. D., and Murray, J. F.: Brit. Heart J. 14: 213, 1952.

72. Wuhrmann, F.: Schw. Med. Woch. 80: 715, 1950.

73. Nickerson, M., Karr, G. W., and Dresel, P. E.: Circulat. Res. 9: 209, 1961.

74. Richardson, H. L., Graupner. K. I., and Richardson, M. E.: J. A. M. A. 195: 114, 1966.

75. Anderson, R. F., Allensworth, D. C., and de Groot, W. J.: Ann. Int. Med. 67: 1172, 1967.

76. Burch, G. E. and Walsh, F. F.: Am. J. Cardiol. 6: 864, 1960.

77. Evans, W.: Prog. Cardiovasc. Dis. 7: 151, 1964.

78. Alexander, C. S.: Am. J. Med. 41 : 213, 1966.

79. Schwartz, A.: Beitr. path. Anat. 136: 316, 1968.

80. James, T. N.: Prog. Cardiovasc. Dis. 7: 43, 1964.

81. Varnauskas, E., Ivemark, B., Paulin, S., and Ryden, B.: Am. J. Cardiol. 19: 531, 1967.

82. Pearse, A. G. E.: Cardiomyopathies, ed. by G. E. W. Wolstenholme and M. O'Connor, J \& A Churdrill Ltd., London, p. 132, 1964.

83. Bajusz, E. and Jasmin, G.: Am. Heart J. 69: 83, 1965.

84. Van Der Geld, H., Peetom, F., Somers, K., and Kanyerezi, B. R.: Lancet ii: 1210, 1966.

85. Burch, G. E., Sun, S. C., Colcolough, H. L., Sohal, R. S., and DePasquale, N. P.: Am. Heart J. 74: 13, 1967. 